\title{
Comprehensive cross production system assessment of the impact of in vitro microenvironment on the expression of messengers and long non-coding RNAs in the bovine blastocyst
}

\author{
Isabelle Côté, Christian Vigneault ${ }^{1}$, Isabelle Laflamme, Joanie Laquerre, Éric Fournier, \\ Isabelle Gilbert, Sara Scantland, Dominic Gagné, Patrick Blondin ${ }^{1}$ and Claude Robert
}

Laboratory of Functional Genomics of Early Embryonic Development, Département des Sciences Animales, Faculté des sciences de l'agriculture et de l'alimentation, Centre de Recherche en Biologie de la Reproduction, INAF, Pavillon

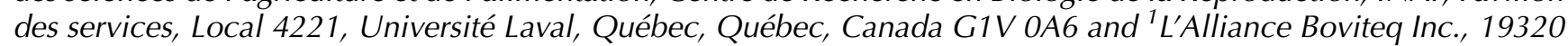
Grand rang St-François, Saint-Hyacinthe, Québec, Canada J2T 5H1

Correspondence should be addressed to C Robert; Email: claude.robert@fsaa.ulaval.ca

\begin{abstract}
In vitro production (IVP) of cattle embryos over the past two decades has revealed several negative impacts that have been attributed to the artificial microenvironment. Studies on embryos produced in vitro clearly point to aberrant gene expression levels. So far, the causal association between phenotype and measured gene expression has not led to substantial improvement of IVP systems. The aim of this study was to generate a unique dataset composed of microarray-derived relative transcript abundance values for blastocysts produced in ten in vitro systems differing primarily in culture medium formulation. Between-group comparisons determine the level of overall similarity among systems relative to in vivo reference embryos. The use of the dataset to contrast all in vitro treatments with the in vivo blastocysts pointed to a single common gene network. The 'boutique' array contained a panel of novel uncharacterized transcripts that were variably expressed depending on the medium in which the blastocysts were produced. These novel transcripts were differentially expressed in blastocysts even as carryover from conditions encountered 7 days earlier during oocyte maturation. All of the selected novel candidates thus expressed were from intergenic regions. The function of this long non-coding RNA remains unknown but clearly points to an additional level of complexity in early embryo development.
\end{abstract}

Reproduction (2011) 142 99-112

\section{Introduction}

The extended use of in vitro production (IVP) techniques for cattle embryos over the past two decades has proven their ability to produce seemingly healthy offspring. In cattle, IVP is primarily employed to palliate infertility and increase the birth rate of high genetic merit animals (Bousquet et al. 1998, 1999, Durocher et al. 2006). The sustainability of early development in vitro widely differs across species. Various systems tested and developed for cattle are now considered efficient for routine commercial production of embryos. The standard reference in artificial reproductive technologies applied to dairy animals is multiple ovulation embryo transfer in which a super-ovulation regimen leads to the production of multiple embryos recovered by uterine flushing a week after artificial insemination. In comparison, recovery of immature oocytes after ovarian stimulation (ovum pickup) that are submitted to IVP can generate four times the amount of transferable embryos by allowing the donor cow to recover among each of several rounds of ovum pickup while embryos are produced ex vivo (Bousquet et al. 1998, 1999, Durocher et al. 2006).

However, the artificial fertilization and early embryo development environment has several shortcomings, that have recently been identified. Among the bestdescribed negative impacts of IVP are the birth of abnormally large calves or 'large offspring syndrome' (Young et al. 1998, McEvoy et al. 2000), the skew in the sex ratio in favor of males (Kimura et al. 2005, 2008), and increased sensitivity to cryopreservation (Rizos et al. 2003, 2008), which hinders the export potential of embryos obtained in vitro. Due to these problems, a large number of studies are conducted to characterize blastocysts produced in vitro and comparing them to their in vivo counterparts to identify the causes of the deleterious effects of IVP and to improve in vitro conditions for embryo development (Wrenzycki et al. 1998, 2001, Niemann \& Wrenzycki 2000, Knijn et al. 2002, 2005, Lonergan et al. 2003, Rizos et al. 2003, 2008, Gutierrez-Adan et al. 2004, Mohan et al. 2004, McHughes et al. 2009, Purpera et al. 2009). As is often 


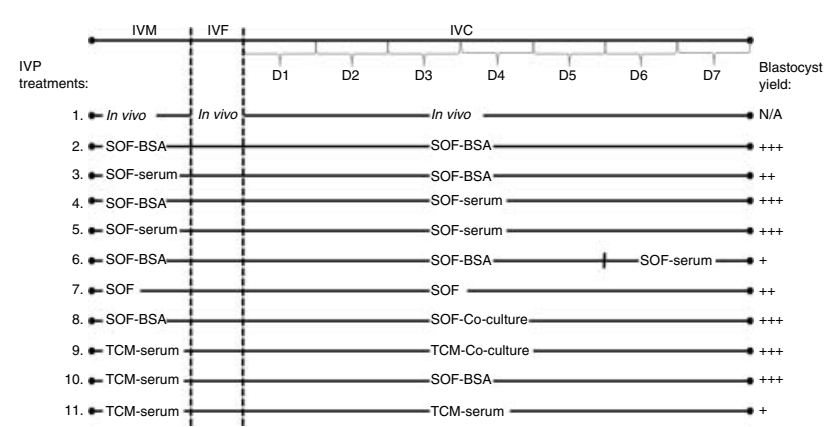

Figure 1 In vitro culture conditions: the oocyte fertilization procedure was identical for all in vitro conditions. TCM, tissue culture medium 199; SOF, synthetic oviductal fluid. Treatment 7 served as a control under suboptimal conditions (i.e. without protein supplementation). Co-culture conditions involved the support of BRL cells grown in the presence of serum. In vivo embryos were collected by uterine flushing 7 days after insemination. The blastocyst yield is a subjective evaluation ranking the systems on their potential to produce high numbers of healthy looking blastocysts.

the case for samples of very small mass such as embryos, most of these studies have focused on gene expression. Significant differences in transcript abundance between in vitro and in vivo embryos have repeatedly been observed using both the candidate gene approach and the comprehensive methods such as microarrays.

A certain degree of plasticity is expected in embryogenesis even in vivo, as the developing embryo adapts to normal changes in the uterine environment, which are not necessarily identical from one mother to the next or even from one gestation to the next. It is, therefore, also expected that in vitro embryos deviate to some extent from the gene expression patterns observed in their in vivo counterparts. Based on the published gene expression studies, it should be possible to define the boundaries of this plasticity and identify key gene pathways involved in embryo development. However, large methodological differences among studies prevent the comparison of their gene lists and their integration into a comprehensive model of embryonic development (Gilbert et al. 2010, Robert 2010, Seli et al. 2010). Linking the observed variations in transcript abundance with the observed phenotypes has been extremely challenging. A database generated from studies based on a standardized methodological approach would facilitate the required comparisons. Therefore, the objective of this study was to generate transcript abundance data from blastocysts produced under a wide range of in vitro conditions. Using a 'boutique' microarray, we were able to contrast ten IVP systems, distinguished by culture media composition and protein supplementation during oocyte maturation or embryo culture, with each other and with in vivo reference embryos. The comparisons between treatment groups offer possibilities for better definition of the concept of embryonic plasticity.

\section{Results \\ Performances of the different embryo production systems}

The ten embryo production systems provided considerable variations in embryo yield (Fig. 1). Blastocyst yield calculated as the percentage of matured oocytes that developed into blastocysts after fertilization is presented in Table 1. The yield ranged from 30 to $40 \%$ for the best-performing systems to $10-20 \%$ for the least. The overall appearance of typical blastocyst cohorts found on day 7.5 of culture for most of the IVP systems is presented in Fig. 2.

Experimental treatments $2-5$ are synthetic oviductal fluid (SOF)-based systems in which BSA and serum supplementation were alternated for the in vitro maturation and in vitro culture steps to produce all plausible combinations (Fig. 1). The blastocyst yields were similar (Table 1) and all treatments produced large, fully expanded blastocysts (Fig. 2). However, in some treatments (most obvious in treatment 7), the morphology of the average blastocyst exhibited some differences being smaller and darker (Fig. 2). In experimental treatment 6 , serum was added on the last 2 days of embryo culture and thus after embryonic genome activation in an attempt to determine whether fully active embryonic cells could better use this hormone-rich supplement. This treatment did not prove beneficial and resulted in a poor blastocyst yield $(\approx 5 \%$ blastocyst yield on day 7.5 of culture). Due to its poor performance, this treatment was dropped from

Table 1 Embryo production yields for different in vitro systems.

\begin{tabular}{|c|c|c|c|c|c|c|c|}
\hline \multirow[b]{2}{*}{$\operatorname{Nos}^{a}$} & \multicolumn{2}{|c|}{ IVP treatment } & \multirow[b]{2}{*}{ COCs } & \multirow[b]{2}{*}{ Cleaved (\%) } & \multirow[b]{2}{*}{ Eight-cell $^{\mathrm{b}}(\%)$} & \multirow[b]{2}{*}{ Blastocyst $^{\mathrm{C}}(\%)$} & \multirow[b]{2}{*}{ Hatched $^{\mathrm{C}}(\%)$} \\
\hline & IVM & IVC & & & & & \\
\hline 2 & SOF-BSA & SOF-BSA & 65 & $55(84.6)$ & $41(63.1)$ & $23(35.4)$ & $11(16.9)$ \\
\hline 3 & SOF-serum & SOF-BSA & 65 & $57(87.7)$ & $39(60.0)$ & 19 (29.2) & $8(12.3)$ \\
\hline 4 & SOF-BSA & SOF-serum & 65 & $60(92.3)$ & $47(72.3)$ & 25 (38.5) & $6(9.2)$ \\
\hline 5 & SOF-serum & SOF-serum & 65 & $58(89.2)$ & $39(60.0)$ & 24 (36.9) & $2(3.0)$ \\
\hline 7 & SOF & SOF & 56 & 48 (85.7) & 39 (69.6) & $18(32.1)$ & $6(10.7)$ \\
\hline 10 & TCM-serum & SOF-BSA & 154 & 137 (90.0) & 95 (61.7) & 53 (34.4) & $15(9.7)$ \\
\hline 11 & TCM-serum & TCM-serum & 187 & $148(79.1)$ & $90(48.1)$ & $38(20.3)$ & $0(0)$ \\
\hline
\end{tabular}

${ }^{\mathrm{a}}$ Data for treatments 6,8 , and 9 are incomplete and were not compiled. ${ }^{\mathrm{b}}$ Eight-cell determined 3 days after fertilization. ${ }^{\mathrm{c}}$ Blastocyst and hatching rates determined 7.5 days after fertilization. 


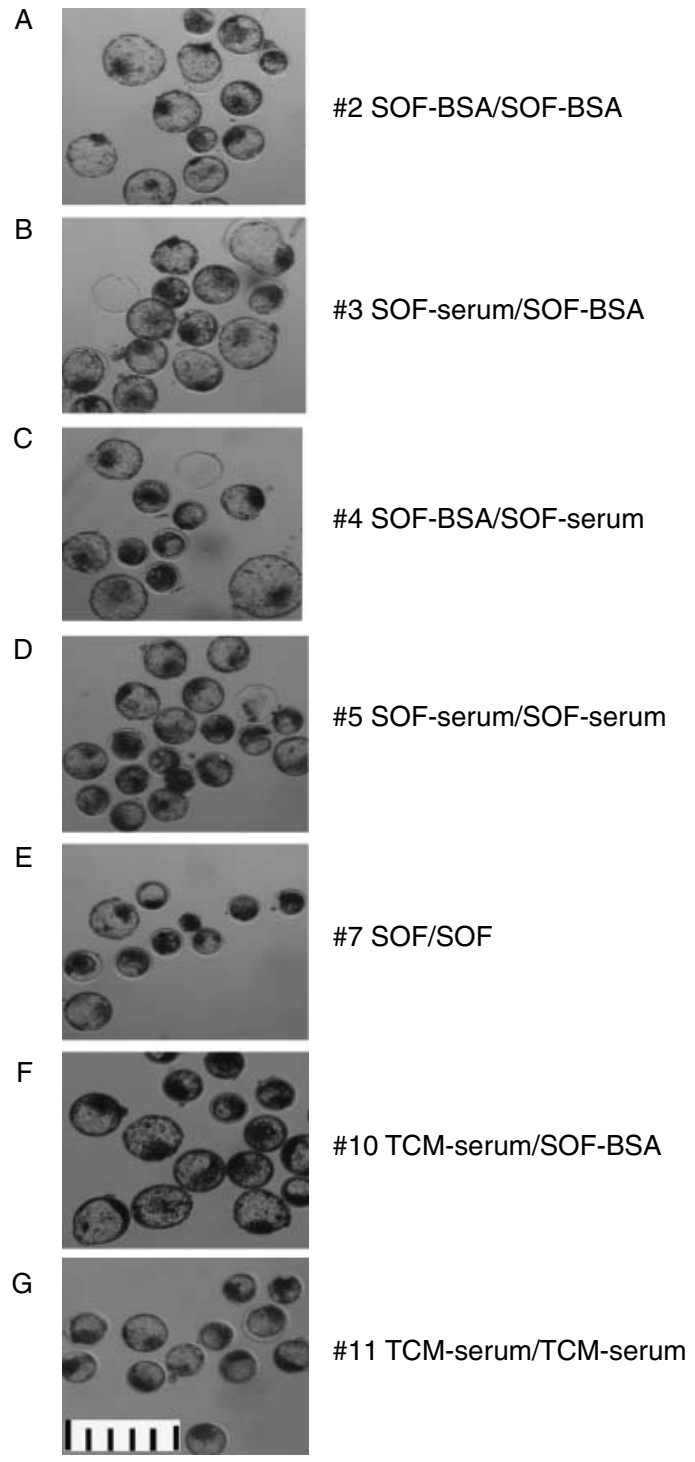

Figure 2 Blastocyst morphology. The different IVP systems resulted in blastocysts of different sizes. Variance in cohort homogeneity can also be observed. Phase contrast images at $400 \times$. Scale increment $=$ $100 \mu \mathrm{m}$. Media are the same as in Fig. 1.

microarray analyses once embryo pools were collected. The control treatment (7), which did not include any protein supplementation and was intended as suboptimal, gave a blastocyst yield (32.1\%) comparable to the moderate to best-yielding systems (Table 1). However, these embryos appeared to be of deviant phenotype, the blastocysts being on average, smaller, and underdeveloped in comparison with those from other high-yielding systems (Fig. 2).

The use of tissue culture medium 199 (TCM) during oocyte maturation led to acceptable yields of embryos (treatments 9 and 10), although its use to support embryo development was detrimental (treatment 11) unless embryos were co-cultured with somatic cells (treatment 9). Performance data collection was incomplete for treatments 8 and 9. They, however, performed as expected for co-culture supported systems, e.g $\approx 30 \%$ of blastocyst yield on day 7.5 of development. These Buffalo rat liver (BRL) cells have widely been used in commercial settings as the supporting monolayer of somatic cells due to their appropriate sanitary status. The presence of somatic cells, even when non-oviductal in nature, is known to condition medium by neutralizing detrimental factor in serum. The different supplementations also suggest that serum is unnecessary for embryonic development in SOF medium (treatments 2, 3 , and 7) and even detrimental (treatment 6).

\section{Microarray data validation}

Although the blastocyst yield is commonly used as an indicator of IVP success, as it is a non-invasive determination of the overall efficiency of the procedure, this parameter provides very little information on the characteristics of the produced embryos. We, therefore, turned to our boutique microarray to determine the expression profile of the embryos produced in the ten IVP systems described above in addition to that of in vivo embryos.

To test the robustness of the microarray dataset, validation was undertaken by qRT-PCR using a panel of candidates. The aim of the validation was to determine whether the relationship between treatments based on RNA abundance values observed by microarray could be confirmed. Comparisons of qRT-PCR transcript abundance and microarray values indicate similar patterns for a high proportion of the candidates for the three tested treatments (Fig. 3). An expressed sequenced tag corresponding to a novel transcribed region (NTR) matching a still unassigned contig on the bovine genome was also tested (Fig. 3). The similar profiles suggest that the dataset does in fact reflect the relationship between IVP systems. As such, analyses were performed to compare the IVP systems overall in order to highlight relationships between them in addition to their distance from the in vivo embryos.

\section{Comparative assessment of blastocyst gene expression across IVP systems}

Hierarchical clustering of microarray data indicates that the closest treatment to the in vivo reference is TCM/TCM co-culture (treatment 9), which also produced one of the best blastocyst yields (Figs 1 and 4). In contrast, when in vitro maturation (IVM) was supported with serum and the culture period supplemented with BSA (treatments 3 and 10), embryos produced expression profiles that clustered away from the main grouping, suggesting a potentially negative impact of the transition from a serum-free to a serum-supplemented environment. The suboptimal control treatment SOF/ SOF (7) grouped with another system leading to a poor 

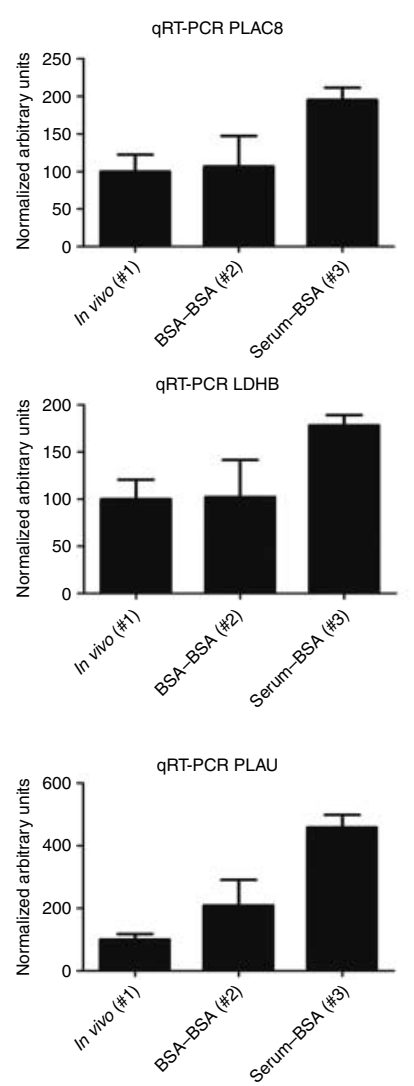
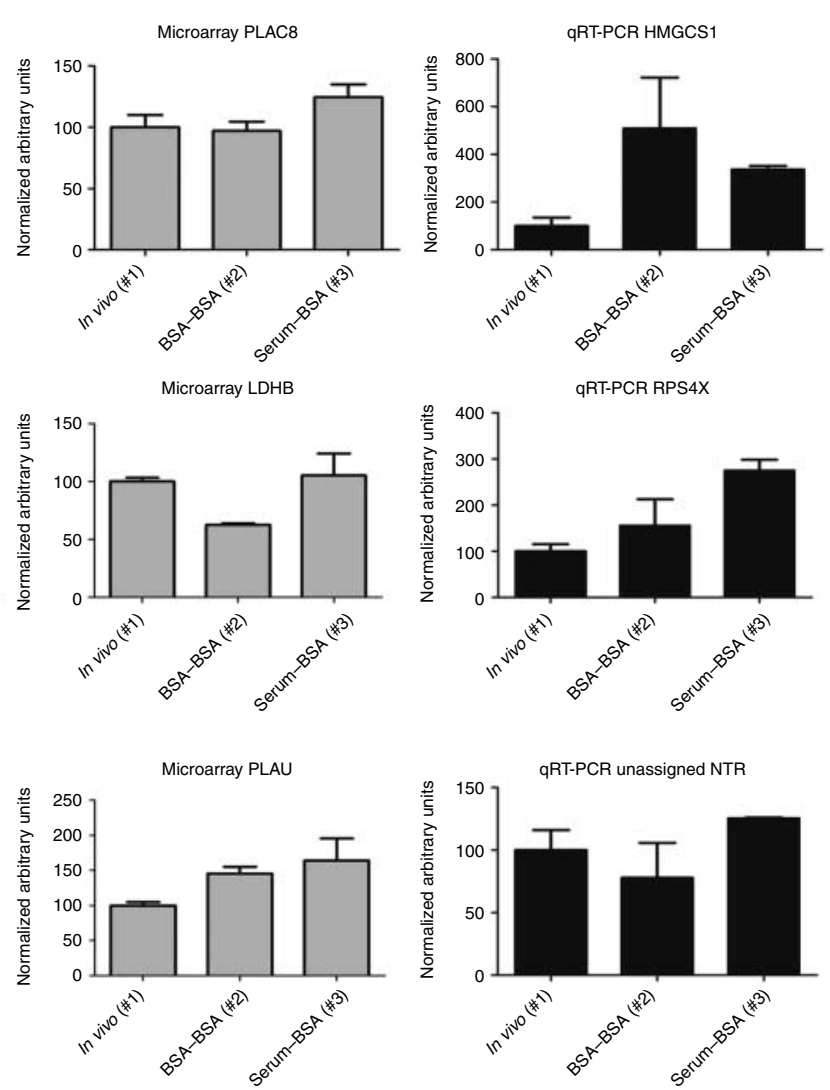
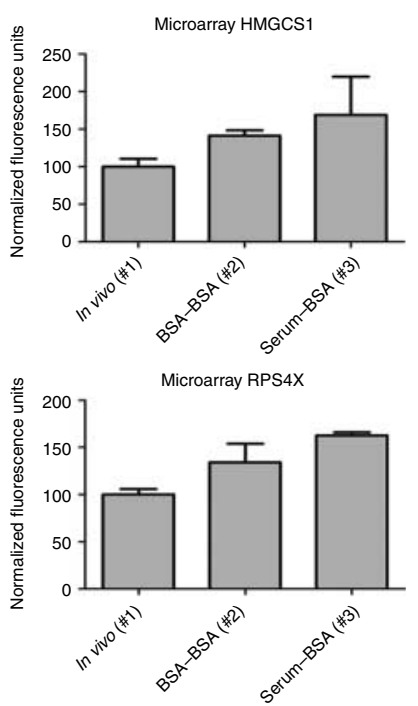

Figure 3 Validation of microarray dataset by qRT-PCR: contrasts were made by comparing the in vitro systems with blastocysts of in vivo origin as the reference. Additional pools of embryos were produced for the qRT-PCR measurements. BSA-BSA =SOF-BSA/SOF-BSA (treatment 2); serum-BSA = SOF-serum/SOF-BSA (treatment 3).

yield (11) and unexpectedly with the SOF-BSA/SOFserum treatment (4), which showed high variability among biological replicates as indicated by the size of the cluster (Fig. 4). This variability detected through gene expression analysis could be indicative of heterogeneity in the embryos produced using this system.

Although treatment 6 (SOF-BSA/SOF-BSA 5d + SOFserum $2 \mathrm{~d}$ ) resulted in a low blastocyst yield, the RNA abundance profile was close to the in vivo reference (Fig. 4A) and grouped with several other SOF-based treatments $(2,5$, and 8$)$ (Fig. 4B). The SOF-serum/SOFserum (treatment 5) produced the greatest variability between biological replicates, observed as the large diameter of the cluster representation (Fig. 4B). Taken together, these profiles indicate that the addition of serum to SOF medium during embryo (treatments 4 and 5) culture leads to more heterogeneous groups of blastocysts compared with BSA-supported or co-culture-supported in vitro culture (IVC).

\section{Impact of culture condition on gene expression of candidates}

At the single gene level, clear differences between treatments and groups of treatments can be seen in the clustering of the differentially expressed genes that harbor the most significant $P$ values (Fig. 5). The most striking result is the presence of numerous 'no match' candidates, which represent NTRs that were positioned on the genome but not found associated with any known genes. This straightforward analysis suggests that novel transcripts represent $18 / 100$ of the candidates most significantly influenced by in vitro conditions in this study.

\section{Impact of embryo culture conditions on the expression of mitochondrial and uncharacterized transcripts}

These observations were confirmed by measuring the abundance of several NTR across a set of SOF-based IVP systems. The results show that this novel RNA class is greatly influenced by the microenvironment, with some treatments rendering the targets undetectable (Fig. 6). The measurements exhibited considerably more variance between replicates than for the protein-coding candidates. The features on the microarray also allowed detection of transcripts originating from both the nuclear and the mitochondrial genomes. We found that IVP conditions also impact mitochondrial gene expression (Fig. 6), clearly indicating that culture conditions influence every level of gene expression including 
A
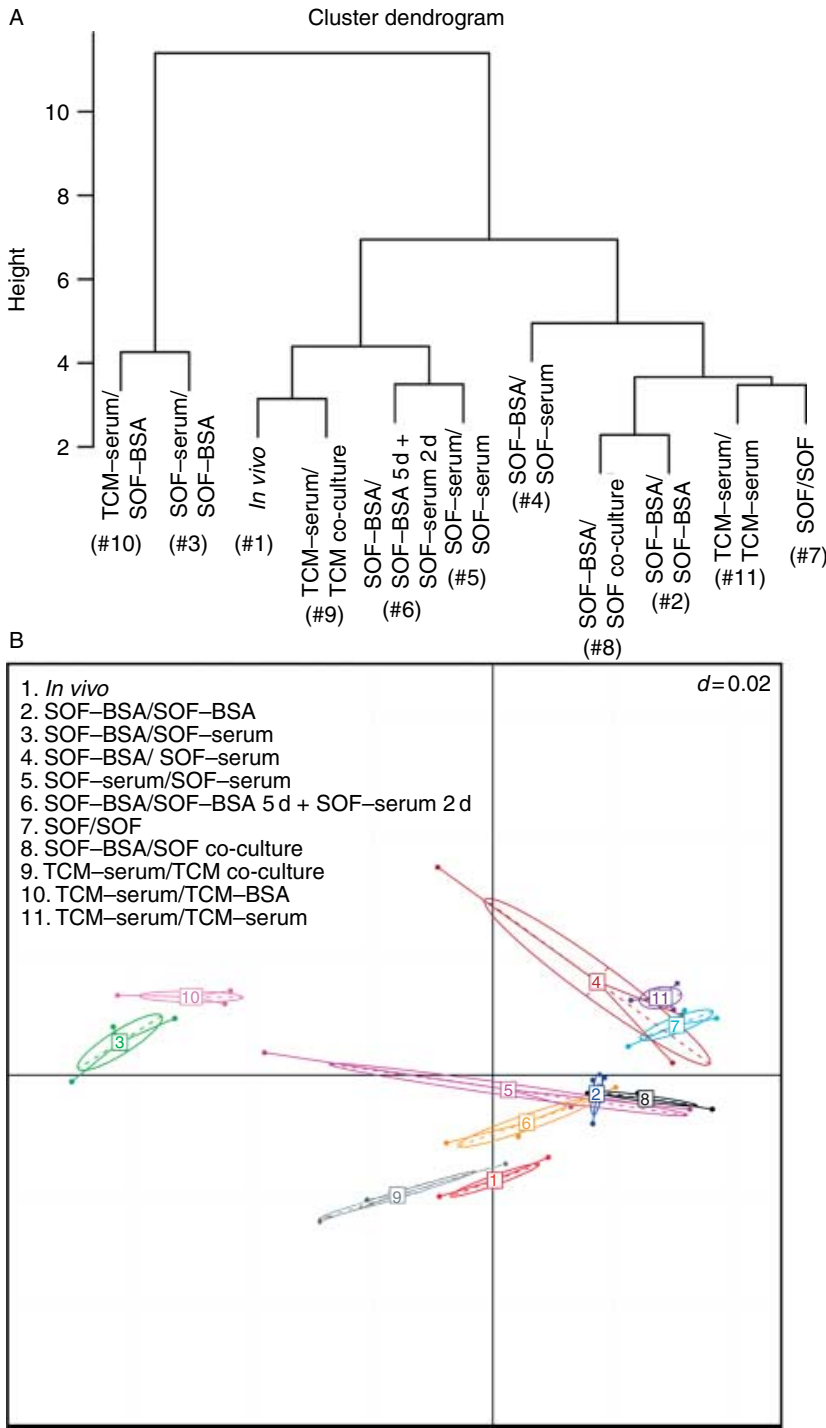

Figure 4 Between-group analyses: (A) cluster dendrogram of the relationship between embryo production systems (reference to treatment number presented in Fig. 1 is indicated). (B) Relationship distances are based on eigen values between production systems. The size of the cluster is indicative of the degree of variation between biological replicates. The media are as in Fig. 1. The in vivo embryos were used as the reference.

protein-coding, non-coding, and transcribed elements found in both the nuclear and the mitochondrial genomes.

\section{Functional analysis of gene expression discrepancies contrasting different IVP systems}

The microarray dataset generated in this study offers the flexibility to contrast different treatments or groups of treatments. The aim of one of the contrasts of interest was to evaluate the impact of serum (added either during IVM or to the embryo culture medium as a supplement) by identifying transcript abundance fluctuations.
As illustrated in Fig. 7, the main pathway identified suggests that embryos produced from oocytes matured in the presence of serum and later supported by BSA during culture display differential expression of genes involved in protein synthesis pathways, while the presence of serum during embryo development has an impact on the poly-ADP ribose polymerase pathway. The top three biological functions associated with the gene network presented in Fig. 7 are cell death, gene expression, and lipid metabolism. Interestingly, the lower hatching rate observed in treatments 4 (SOF-BSA/SOF-serum) and 5 (SOF-serum/SOF-serum) compared with the serum-free system (2) may be attributable to increased cell death (Table 1). These functions also fit with the most recognized impact of serum supplementation, which is lipid-over accumulation. A list of all significant biological functions influenced by the presence of serum during either IVM or IVC is presented in Fig. 8. Many of these functions are relevant to the cellular interactions and organization that form the basis of blastocyst formation.

Notwithstanding the diverse nature of the IVP systems in this study, data from all treatments were pooled and contrasted with the in vivo reference in order to find differentially expressed transcripts across all treatments and thus common to any in vitro conditions. This analysis generated a short list of 33 candidates including nine novel transcripts and six ESTs yet to be sequenced. We note with interest that 15 of the remaining candidates bearing an official gene annotation and function-related information pointed to a single cellular pathway (Fig. 9). The top three biological functions associated with this network are gene expression, cellto-cell signaling (i.e. between blastomeres), and cellular movement, the latter two being essential to blastocyst formation and ultimately interaction between the early embryo and the uterine epithelium. It is also noteworthy that all candidates except one were over-expressed in vitro compared with in vivo, indicating that in vitro embryos may indeed be metabolically more active.

\section{Discussion}

IVP of bovine embryos is practiced worldwide both for research and for breeding purposes in the dairy industry. The commercial context of bovine embryo production has led to the production of records that have made it possible to study the potential impact of this assisted reproductive technology (van Wagtendonk-de Leeuw et al. 2000). Short-term effects such as higher or lower cell number (Fischer-Brown et al. 2002), altered sex ratio (Kimura et al. 2005, 2008), changes in developmental kinetics (Holm et al. 2002), and lower tolerance to cryopreservation (Rizos et al. 2003) and long-term effects such as large offspring syndrome (Young et al. 1998) and increased frequencies of abnormalities and spontaneous abortion (Taverne et al. 2002) are well documented. The mechanistic causes of 


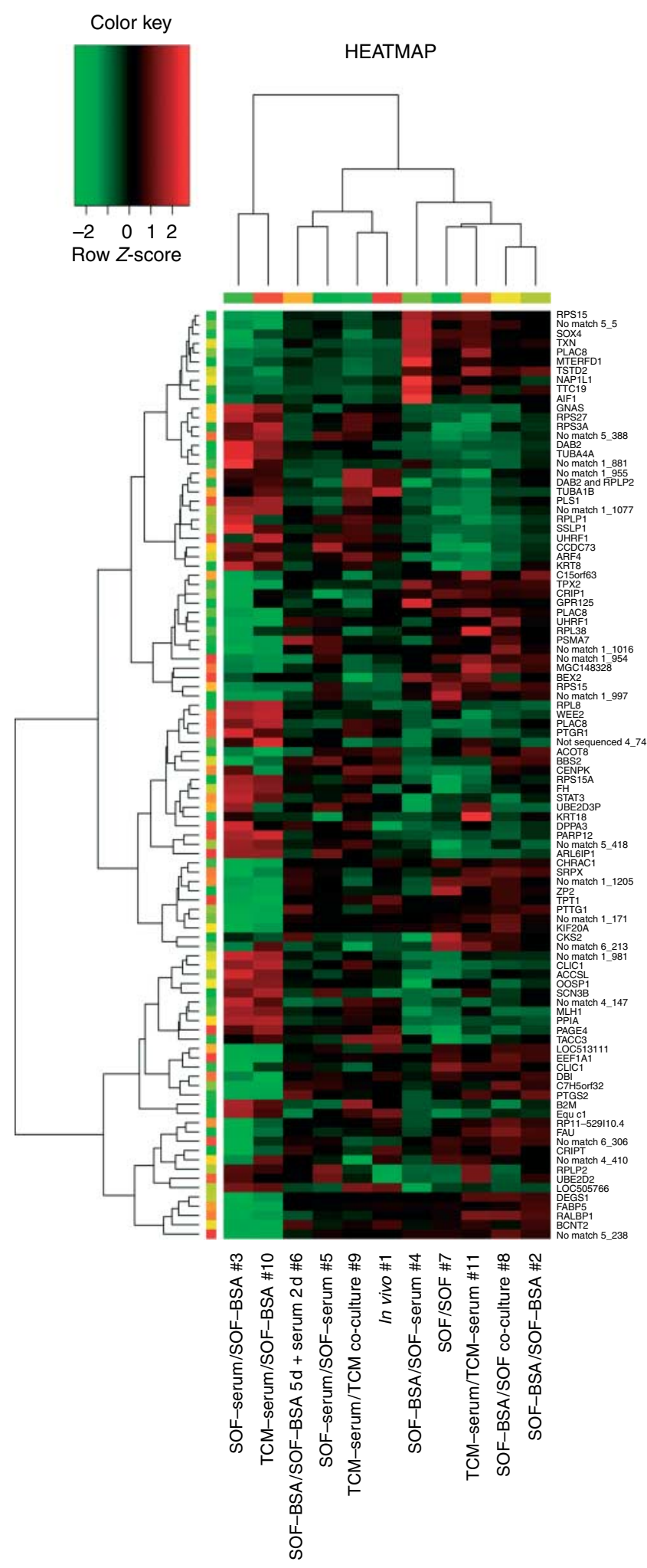

Figure 5 Clustering of co-regulated genes for the various embryo production systems. Heat map from the 100 candidates with the most significant $P$ values. Reference to treatment number presented in Fig. 1 is indicated. these phenotypes have not yet been elucidated. It is widely accepted that although bovine blastocysts can be produced under a wide range of in vitro conditions with some success, IVP in its present state of development clearly provides suboptimal conditions. So far, the most common basis of comparison between IVP systems remains the percentage of zygotes reaching the blastocyst stage (Menck et al. 1997, de Moraes \& Hansen 1997, Guyader-Joly et al. 1999, Luciano et al. 1999, Stojkovic et al. 2002, Alm et al. 2005, Fujita et al. 2006, Block et al. 2009, Pereira et al. 2010). However, blastocyst yield might not be an appropriate measurement of IVP efficiency if embryo quality is defined as the potential for healthy gestation and successful coping with stresses such as cryopreservation and transfer protocols. Indeed, molecular study on the responses of embryos to different conditions would greatly improve our understanding of early embryo development and no doubt lead to the development of highly efficient culture systems. In recent years, gene expression analysis has proven to be a powerful tool for such evaluation and its application to studying the effects of IVC media on bovine embryos appears timely.

Although many comparisons of in vivo and in vitro embryos have been published, the lack of uniformity among the methods used impedes the integration of this information into a much-needed overall appreciation of the concept of embryo developmental plasticity. The relative impacts of the different IVP systems and the extent to which these systems produce comparable embryos have not been adequately described. Although a certain level of developmental plasticity is expected, the degree of similarity between blastocysts produced using different IVP systems is not known. As anticipated, significant differences between the blastocyst yields of the ten IVP systems were observed on day 7.5 after fertilization. By combining blastocyst yield information, the overall appearance of the embryos and comparison of gene expression profiles, we seek to elucidate the similarities and differences between blastocysts produced using these various IVP systems and determine the conditions that yield embryos most similar to their in vivo counterparts. Overall, the observed yields and phenotypes for the standard IVP systems routinely employed worldwide (treatments 2, 3, 4, 5, 8, 9, and 10) were within expectations. However, one of the experimental treatments (6: SOF-BSA/SOF-BSA 5 days + SOF-serum 2 days) yielded fewer blastocysts, although the overall gene expression of the resulting embryos matched that of in vivo embryos more closely. Meanwhile, good blastocyst yields in some cases led (e.g. treatments 4 and 5) to the greatest divergence between replicates and the farthest clustering from the in vivo reference, suggesting that adding serum to the IVC medium results in a more heterogeneous blastocyst population. These observations may be due to stimulation and survival of embryos that otherwise would have died. 

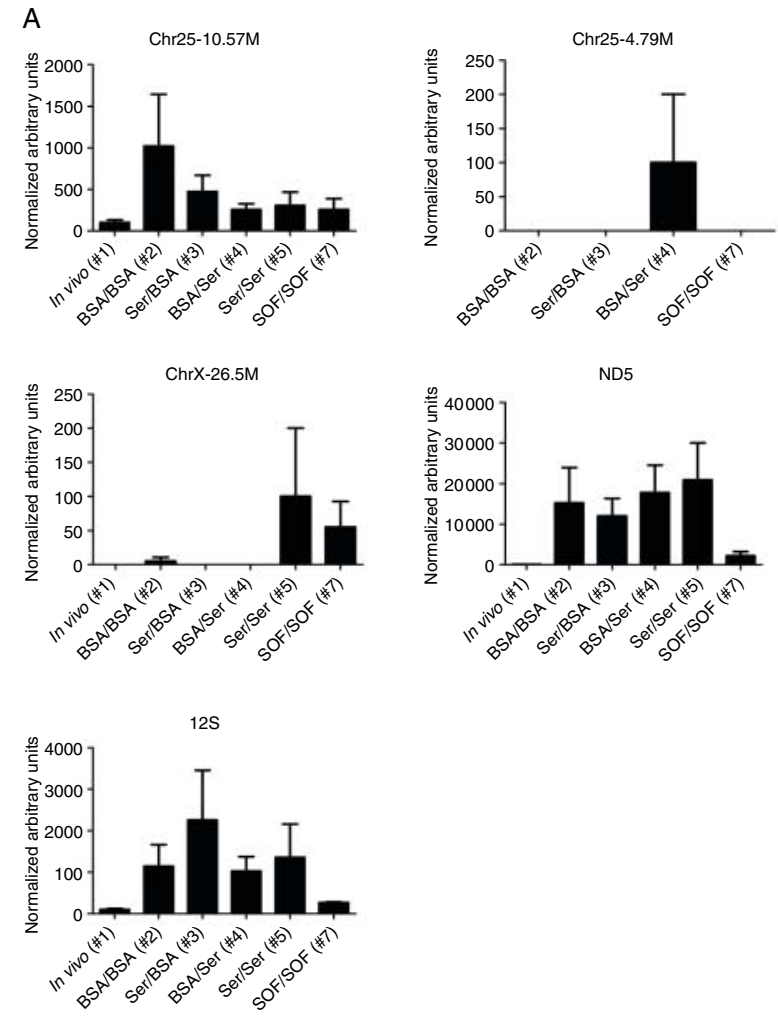

B

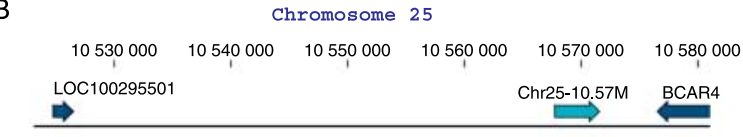

$4200000 \quad 4400000 \quad 4600000 \quad 4800000 \quad 5000000 \quad 5200000 \quad 5400000$ ALG21 LOC521021 Chr25-4.79M FOX1
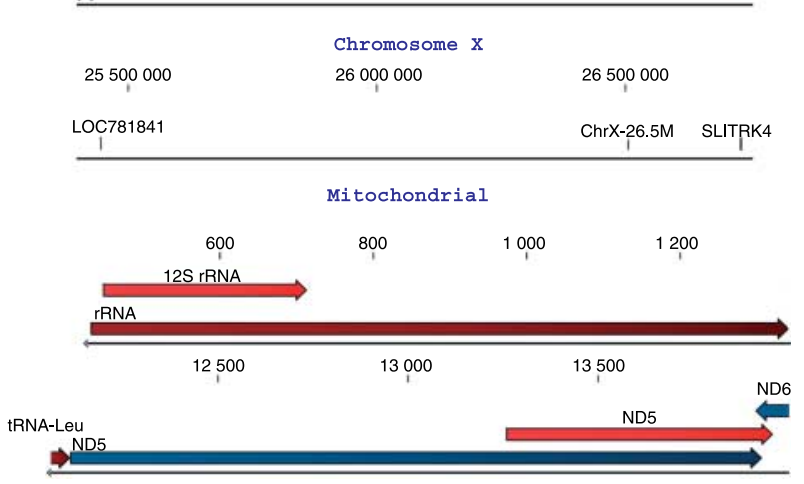

Figure 6 Influence of IVP conditions on abundance measurements of long non-coding RNA and mitochondrial transcripts. (A) qRT-PCR measurements across different SOF-based in vitro systems. The IVM and IVC conditions are indicated for all in vitro systems. In vivo embryos were included as a reference treatment for most targets. Chr25-10.57M, Chr25-4.79M, and ChrX-26.5M are nuclear IncRNA, whereas ND5 and 12S are mitochondrial targets. Reference to treatment number presented in Fig. 1 is indicated. (B) Localization of the expressed sequence tag on the nuclear and mitochondrial genome. The bright red arrow indicates the mitochondrial expressed sequence tags found on the microarray.
Taken together, these results bring a novel perspective to the quest to define high-yielding IVP systems where the use of these suboptimal conditions can act as a mean to select the most robust embryos that exhibit the best developmental competence. In a situation where the exposure to such suboptimal conditions does not lead to long-term dire effects, this selection and homogenization of the embryonic cohort could be beneficial in maximizing the transfer of the best embryos. Embryo quality remains a vague concept, but these results suggest that the combination of morphological characteristics with overall gene expression profiling could provide more efficient means of describing and distinguishing the functional characteristics of groups of embryos.

At the gene level, relative transcript abundance analysis has proven to be challenging. Although a daunting task, associating fluctuations in gene expression with deleterious phenotypes has considerable potential for identifying faulty gene pathways and suggesting improvements to culture conditions. We have previously found that the comparison of gene lists is another endeavor hindered by methodological considerations. In benchmarking our own microarray platform, we recently reported the major impact of sample processing procedures on gene expression results (Gilbert et al. 2009, 2010). For instance, the correlation values between different sample amplification procedures, which are inherent when working with early embryos, were in the range of 0.35 (Gilbert et al. 2010). By generating our dataset from a single standardized methodological platform, we hoped to ensure the validity of all of the comparisons made.

One of the specific aims of this study was to determine the impact of serum supplementation on gene expression in embryos cultured in IVM and IVC media. We note with interest that among the biological functions differentially affected between these two phases were general cellular functions and also functions (e.g. lipid metabolism) that could be associated with observable phenotypes. It has been clearly shown that in vitro produced embryos are generally darker due to lipid over-accumulation, which translates into a lower tolerance to cryopreservation (Crosier et al. 2000, Rizos et al. 2003). Furthermore, in contrasting the in vitro treatments with the in vivo reference, only one gene network clearly emerged as being involved in the phenotypes displayed by IVP embryos even though several gene networks were expected. Although the biological functions associated with this network are broad, the fact that all of its genes (with the exception of peptidylprolyl isomerase A or PPIA, also known as cyclophilin A) were over-expressed in in vitro embryos could be related to the 'quiet embryo' theory (Leese 2002, Leese et al. 2007). It has recently been proposed that the best embryos would be those with the lowest metabolism and thus overall lower level of gene expression. Leese et al. (2008) propose two 


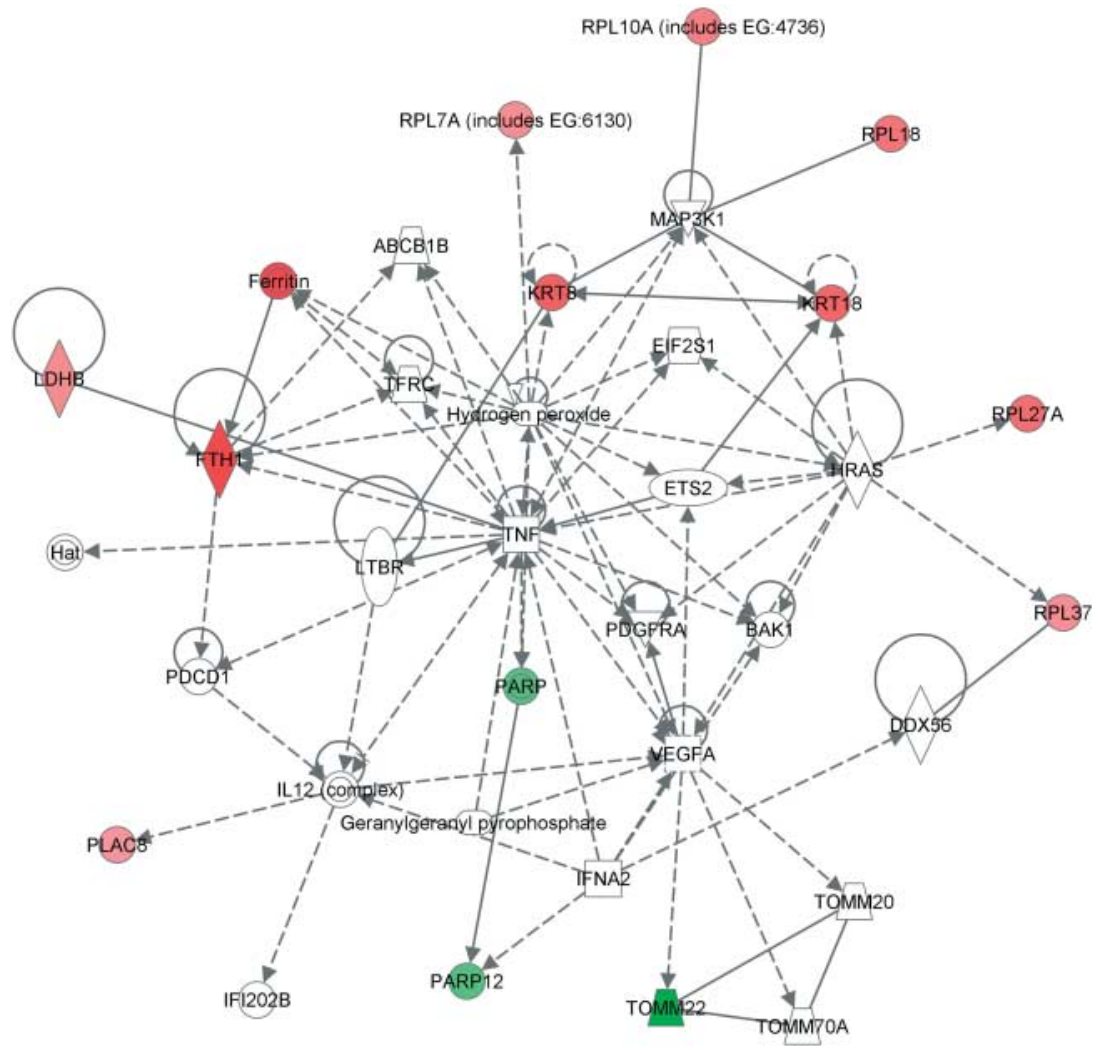

Figure 7 Pathway influenced by the presence of serum during either IVM or IVC (treatments 3 and 4). Data was generated by contrasting treatments 3 and 4 (SOF-serum/SOF-BSA versus SOF-BSA/SOF-serum). Red= over-expressed when serum is added during oocyte maturation; green $=$ over-expressed when serum is added during embryo culture. categories of 'quietness' within a cohort of embryos: the metabolically less active condition being more viable (inter-individual quietness) and 'loss of quietness' occurring in response to stress such as the culture environment. This hypothesis is still debated and it is not clear why a higher metabolic state confers lower developmental potential rather than increasing means of coping and compensating.

Our results clearly indicate that culture conditions not only impact protein-coding transcripts but also noncoding RNA in both the nuclear and the mitochondrial genome. In fact, the most compelling attribute of the clone collection featured on the 'boutique' array used in this study is the presence of uncharacterized transcripts $(n=161)$. By assembling a clone collection without relying on a priori knowledge, we were able to isolate a set of NTR, of which the abundance is impacted by embryo production systems. The roles of these long uncharacterized transcripts still remain to be elucidated. All of the novel candidates confirmed as being influenced by culture conditions are presumed to be long non-coding RNA (IncRNA) because they are located in intergenic regions in which the known flanking genes were found to be several dozen $\mathrm{kb}$ away. It is highly probable that the clones assembled for printing on the microarray are partial in the case of these novel sequences. The full transcript structure is unknown but the cloned sequences did not harbor any open reading frame that would be indicative of a proteinencoding transcript.

The cellular functions of IncRNA are still unclear, but some of the best-studied examples such as $\mathrm{H} 19$ and the $X$-specific inactivating transcript (Xist) have been shown to play crucial roles during early development (Rougeulle \& Avner 2004, Senner \& Brockdorff 2009). The action of these IncRNA, along with small noncoding RNA (which include micro-RNA), is part of the epigenomic regulation of gene expression. The finding that these IncRNA are influenced by culture conditions clearly highlights the level of complexity inherent in early development. It is still unknown whether these IncRNA are indicative of faulty chromatin structure rendering their expression permissive, which would corroborate reports suggesting that culture conditions and embryonic manipulation can perturb the epigenome (Le Bouc et al. 2010, Santos et al. 2010), or if they are involved in a deliberate response that enables the embryo to cope with culture conditions. Genomic assembly of these ESTs and functional analyses through their knock down is underway. Our results showing that, in addition to protein encoding RNAs, mitochondrial RNAs and also IncRNAs are important component of the embryonic transcriptome corroborates results from Bui et al. (2009). However, in this report, quantification of one of the retrotransposons at the morulae stage showed similar levels between in vitro fertilized and 


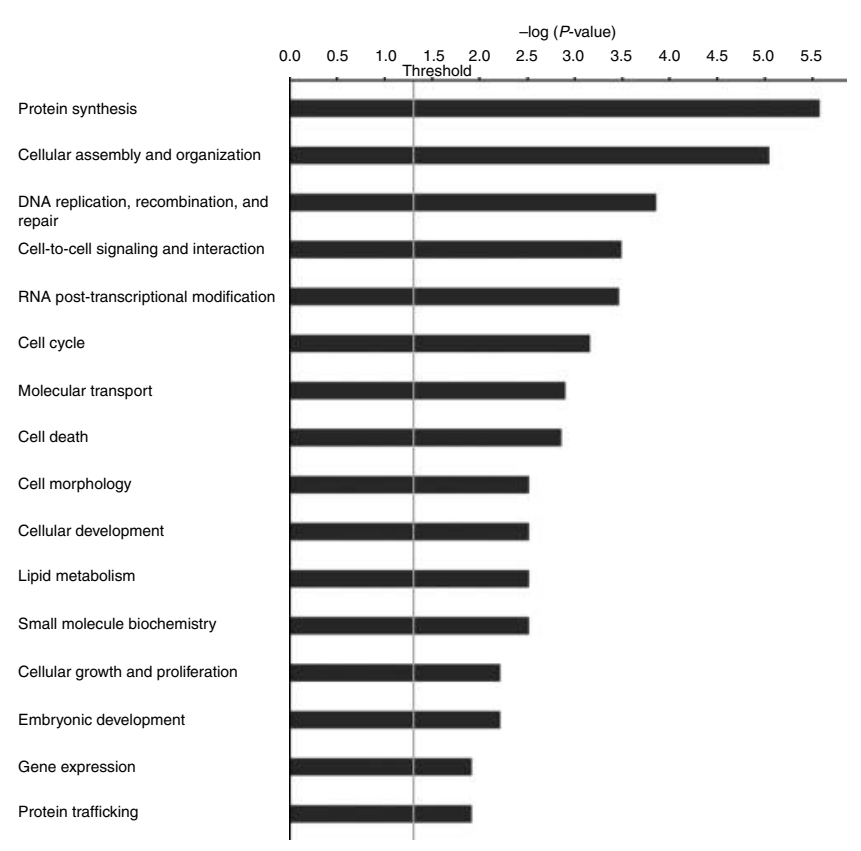

Figure 8 List of biological functions impacted by serum supplementation either during IVM or IVC (contrasting treatments 3 and 4). Significance threshold is indicated.

cloned from somatic cell nuclear transfer (SCNT) counterparts, which is indicative of normal reprogramming (Bui et al. 2009). In contrast, we report in this study that the in vitro culture environment is influencing the level of expression of IncRNAs. It could then be expected that increased embryonic manipulations such as performed on SCNT embryos would lead to aberrant expression of retrotransposons. The fact that both embryonic types were submitted to the same IVP system and both involved selection of morphologically similar embryos may explain this apparent discrepancy between studies. A better understanding of the potential roles of these IncRNAs during early development most certainly requires further investigation.

\section{Conclusion}

The dataset generated in this study enabled to perform comparisons that provided more information about IVP systems than does standard determination of developmental rate alone. They also provided details that are complementary to work already published and suggest additional parameters for defining the concept of embryo quality, such as cohort homogeneity. Finally, to our knowledge, this is the first study reporting that the expression of novel IncRNA is influenced by IVP conditions.

\section{Materials and Methods}

All chemicals were obtained from Sigma-Aldrich unless stated.

\section{Embryo production}

Production of in vivo blastocysts

The ovarian stimulation protocol, artificial stimulation, and uterine flushing were conducted as described by Bousquet et al. (1999).

\section{Oocyte maturation}

Ovaries from dairy cows were collected at the slaughterhouse and processed as described previously. Cumulus oocyte complexes (COCs) were washed in HEPES-buffered Tyrode's lactate (TLH) medium supplemented with 10\% (V/V) FCS and placed in groups of ten in pre-equilibrated $50 \mu$ droplets of oocyte maturation medium (see below) covered by mineral oil. After the distribution of the COCs, the drops were topped with $0.1 \mu \mathrm{g} / \mathrm{ml} \mathrm{FSH}$ (Gonal-f, Serono) and $1 \mu \mathrm{l} / \mathrm{ml}$ estradiol (Sigma \#E2758). The following oocyte maturation media were used:

1. TCM (Invitrogen \#11150) supplemented with $10 \%$ (v/v) FCS (or 'serum').

2. SOF (Holm et al. 1999, Vigneault et al. 2009) supplemented with $10 \%(\mathrm{v} / \mathrm{v})$ FCS.

3. SOF supplemented with $0.8 \%$ BSA fraction $V$ (Sigma).

4. SOF without protein supplementation.

Oocyte maturation was conducted for $24 \mathrm{~h}$ at $38.5^{\circ} \mathrm{C}$ under a humidified atmosphere stabilized at $5 \% \mathrm{CO}_{2}$.

IVF

COCs were recovered from the maturation droplets and washed twice in TLH medium containing $3 \mathrm{mg} / \mathrm{ml}$ fatty acidfree BSA. An additional wash was performed in equilibrated IVF medium (Tyrode's medium supplemented with $6 \mathrm{mg} / \mathrm{ml}$ fatty acid-free BSA). COCs were then transferred to the fertilization chamber in groups of five, each in a $48 \mu \mathrm{l}$ droplet of IVF medium. On transfer, each droplet was supplemented with $2 \mu \mathrm{l}$ of a solution containing $2 \mathrm{mM}$ penicillamine (cat \# P4875), $1 \mathrm{mM}$ hypotaurine (cat \# PH1384), and $250 \mu \mathrm{M}$ epinephrine (cat \# E4250).

Semen was a gift from the Centre d'insémination artificielle du Québec (CIAQ). It consisted of a pool of ejaculates from five different bulls. Standard fertility parameters were assessed according to commercial standards and semen was prepared for IVF as described previously to obtain a final concentration of $25 \times 10^{6}$ spermatozoa per $\mathrm{ml}$, of which $2 \mu \mathrm{l}$ was added to each COC-containing IVF droplet. IVF took place in an incubator $\left(5 \% \mathrm{CO}_{2}\right)$ for $18 \mathrm{~h}$ at $38.5^{\circ} \mathrm{C}$.

\section{In vitro embryo development}

The presumed zygotes were collected and transferred to Eppendorf tubes containing TLH supplemented with BSA and gentamicin. Cumulus cells were then stripped from the zygote by repeated pipetting. The denuded zygotes were washed in $\mathrm{Ca}^{2+} / \mathrm{Mg}^{2+}$-free PBS supplemented with $0.3 \%$ BSA and gentamicin. Embryos were then distributed in culture droplets of the following composition:

1. SOF with $0.8 \%$ fatty acid-free BSA.

2. SOF supplemented with $10 \%(\mathrm{v} / \mathrm{v})$ FCS. 


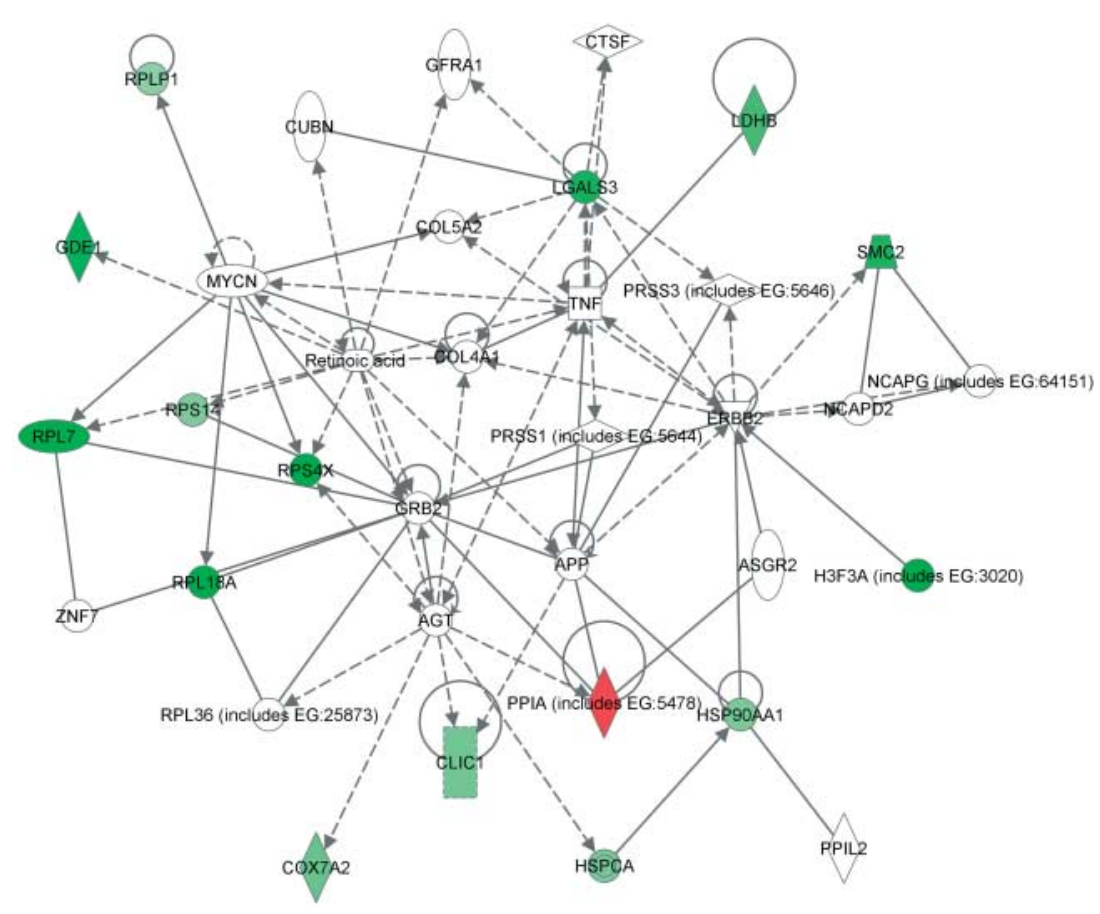

Figure 9 Pathway influenced by the in vitro conditions across all tested systems. Data were generated from the contrast of all in vitro systems (treatments 2-11) with the in vivo reference (treatment 1). Red=over-expressed in in vivo blastocysts; green $=$ over-expressed in in vitro embryos.
3. SOF without BSA or FCS (without protein supplementation).

4. TCM supplemented with $10 \%(\mathrm{v} / \mathrm{v})$ FCS.

5. SOF with $0.8 \%$ fatty acid-free BSA for the first 5 days of culture followed by a transfer in droplets containing SOF supplemented with $10 \%(\mathrm{v} / \mathrm{v})$ FCS for the last 2 days of culture.

6. Co-cultured (SOF or TCM) with BRL cells (co-culture) (with $10 \%(v / v)$ FCS $)$.

Embryo development was conducted in a controlled atmosphere $\left(5 \% \mathrm{CO}_{2}, 7 \% \mathrm{O}_{2}\right.$, and maximum humidity at $38.5^{\circ} \mathrm{C}$ ). Blastocysts were collected 7.5 days after fertilization and pooled in groups of ten. Samples were frozen and kept at $-80^{\circ} \mathrm{C}$ until RNA extraction.

\section{Microscopy}

Images of blastocyst groups were taken using a Zeiss stereomicroscope with a $40 \times$ objective. The images were captured using a digital camera mounted on the microscope.

\section{Experimental design}

A summary of all of the treatments is shown in Fig. 1. Blastocysts obtained in vivo were used as the reference in all comparisons with IVP systems. For all ten in vitro systems, oocyte fertilization was conducted using the same procedure (medium, semen source, and preparation). Oocyte maturation and embryo development were conducted using combinations of two culture media (TCM or SOF), supplemented with either BSA or FCS. Some production systems included the culture of embryos with the support of feeder cells (co-culture). A production system (SOF/SOF) was used as a suboptimal control condition.
For this system, blastocysts were produced in SOF medium without any protein supplementation. For each production system, three biological replicates were done. Technical duplicates for each of these 33 samples were analyzed to generate a dataset composed of 66 microarray hybridizations. The microarray dataset is publically available at the GEO Omnibus repository (GEO accession number: GSE27872).

\section{Description of the microarray}

The BlueChip microarray version 1.2 (Vallee et al. 2009) was used in this study. This microarray contains cDNAs collected from four subtracted libraries (two libraries for isolating transcripts prevalent in oocytes or blastocysts by using a pool of somatic cells as driver while the other two libraries compared oocytes and blastocysts together on the forward and reverse subtractions) generated as published previously (Robert et al. 2000). Each microarray contains a total of 1232 features, each spotted twice. Among these features, 1066 are unique (740 candidates with a RefSeq ID, 161 novel transcripts, 129 not sequenced, and 36 uncharacterized loci) and 166 are controls (negative: two types of Spot Report Alien cDNA Array Validation System (Stratagene, La Jolla, CA, USA, $n=16$ ); $\mathrm{H}_{2} \mathrm{O} / \mathrm{DMSO}$ $(n=50) ;$ GFP $(n=28) ;$ arabidopsis $(n=8)$; empty $(n=32)$; positive: ubiquitin $(n=8) ; \alpha$-tubulin $(n=8) ; \beta$-actin $(n=8))$.

\section{Microarray experiments}

\section{RNA extraction}

Total RNA (from pools of ten blastocysts) was extracted using PicoPure columns (Molecular Devices, Sunnyvale, CA, USA) following the manufacturer's instructions. A DNAse (Qiagen) 
Table 2 PCR primer sequences and reaction conditions.

\begin{tabular}{|c|c|c|c|c|c|}
\hline Gene name & Gene symbol & Primer sequences $5^{\prime}-3^{\prime}$ & $\begin{array}{l}\text { Amplicon } \\
\text { size (bp) }\end{array}$ & $\begin{array}{c}\text { Annealing/ } \\
\text { acquisition } \\
\text { temperature }\left({ }^{\circ} \mathrm{C}\right)\end{array}$ & $\begin{array}{l}\text { Accession } \\
\text { number }\end{array}$ \\
\hline Placenta-specific 8 & PLAC8 & $\begin{array}{l}\text { F: TCGCCATGAGGACAATGTATCGGA } \\
\text { R: GCTTGAGTTGACAAAGGGCACAGA }\end{array}$ & 108 & $50 / 80$ & BC114195 \\
\hline Lactate dehydrogenase B & $\angle D H B$ & $\begin{array}{l}\text { F: CAGTGTCAACAATGGTGAAGGGCA } \\
\text { R: GCAAGCATTAAAGCAAGCATGGGC }\end{array}$ & 346 & $60 / 82$ & BC102217 \\
\hline $\begin{array}{l}\text { Plasminogen activator, } \\
\text { urokinase }\end{array}$ & $P L A U$ & $\begin{array}{l}\text { F: AGTCTGGTTTCCCATGAGGTGTGT } \\
\text { R: TGAGTGTTGATCCAGGGCAGGAAT }\end{array}$ & 254 & $60 / 86$ & BC122657 \\
\hline $\begin{array}{l}\text { 3-Hydroxy-3-methylglutaryl- } \\
\text { CoA synthase } 1\end{array}$ & HMGCS1 & $\begin{array}{l}\text { F: CAAGCCCTGCTAAGAAAGTGCCAA } \\
\text { R: TGAAGTCCTCCACCTCACAGAAGT }\end{array}$ & 110 & $59 / 80$ & AY581197 \\
\hline $\begin{array}{l}\text { Ribosomal protein S4, } \\
\text { X-linked }\end{array}$ & RPS4X & $\begin{array}{l}\text { F: CCATTCAGATTGACTTGGAGACTGGC } \\
\text { R: AGAGAGATCCACGGTTTGTTGCCT }\end{array}$ & 238 & $60 / 80$ & XM_001249535 \\
\hline $\begin{array}{l}\text { Mitochondrially encoded } \\
\text { NADH dehydrogenase } 5\end{array}$ & ND5 & $\begin{array}{l}\text { F: CGAAAACAACCCCCTTCTG } \\
\text { R: AGGCGTTTGAGGGGTAGTG }\end{array}$ & 227 & $50 / 78$ & NC_006853 \\
\hline $12 S$ rRNA & $12 S$ & $\begin{array}{l}\text { F: GCAAGCATCTACACCCCAGT } \\
\text { R: GCTGGCACGAGATTTACCA }\end{array}$ & 195 & $58 / 83$ & NC_006853 \\
\hline Novel transcribed region & Chr25-4.79M & $\begin{array}{l}\text { F: GGTCCTGAACAGCGTGTGT } \\
\text { R: TGATGTGCAGAGGCAAACA }\end{array}$ & 248 & $58 / 85$ & NA \\
\hline Novel transcribed region & Chr25-10.57M & $\begin{array}{l}\text { F: GGATCGCAAGACGTTACTCC } \\
\text { R: CAAAGTCCCAAGGAGGTTCA }\end{array}$ & 243 & $56 / 78$ & NA \\
\hline Novel transcribed region & ChrX-26.5M & $\begin{array}{l}\text { F: CAGAATCGCATGGTTGAGTG } \\
\text { R: TGCAGGAGGTGTTTCCAAG }\end{array}$ & 213 & $56 / 76$ & NA \\
\hline Novel transcribed region & Unassigned & $\begin{array}{l}\text { F: GTAGGACTTGTGCTAGGGCG } \\
\text { R: CATGTGGCTCCTAGCCTGAG }\end{array}$ & 246 & $55 / 83$ & NA \\
\hline$\beta$-Actin & ACTB & $\begin{array}{l}\text { F: ATCGTCCACCGCAAATGCTTCT } \\
\text { R: GCCATGCCAATCTCATCTCGTT }\end{array}$ & 101 & $59 / 80$ & NM_173979 \\
\hline $\begin{array}{l}\text { Conserved helix-loop-helix } \\
\text { ubiquitous kinase }\end{array}$ & CHUK & $\begin{array}{l}\text { F: TGATGGAATCTCTGGAACAGCG } \\
\text { R: TGCTTACAGCCCAACAACTTGC }\end{array}$ & 180 & $57 / 81$ & NM_174021 \\
\hline Green fluorescent protein & GFP & $\begin{array}{l}\text { F: GCAGAAGAACGGCATCAAGGTGAA } \\
\text { R: TGGGTGCTCAGGTAGTGGTTGT }\end{array}$ & 143 & $59 / 89$ & NA \\
\hline $\begin{array}{l}\text { Glyceraldehyde-3-phosphate } \\
\text { dehydrogenase }\end{array}$ & GAPDH & $\begin{array}{l}\text { F: CCAACGTGTCTGTTGTGGATCTGA } \\
\text { R: GAGCTTGACAAAGTGGTCGTTGAG }\end{array}$ & 217 & $58 / 84$ & NM_001034034 \\
\hline $\begin{array}{l}\text { Tyrosine 3-monooxygenase/ } \\
\text { tryptophan 5-monooxygenase } \\
\text { activation protein, zeta } \\
\text { polypeptide }\end{array}$ & $Y W H A Z$ & $\begin{array}{l}\text { F: GCAGAAGAACGGCATCAAGGTGAA } \\
\text { R: CTTCAGCTTCGTCTCCTTGG }\end{array}$ & 286 & $55 / 79$ & NM_174814 \\
\hline
\end{tabular}

treatment was performed on column. RNA samples were amplified through two rounds of in vitro transcription (IVT) using the RiboAmp amplification method (Molecular Devices) according to the manufacturer's recommendation with one modification. During the second amplification round, aminoallyl-coupled nucleotides were added for labeling purposes. During this second amplification reaction, the IVT Master Mix was replaced with the amino-allyl mix (Molecular Devices). Microarray hybridization samples consisted of $5 \mu \mathrm{g}$ aminoallyl-containing aRNA labeled with Alexa 647 dye (Invitrogen). Chemical bonding of the dye to amino-allyl groups was performed following the manufacturer's instructions. Unincorporated dye molecules were removed by purifying samples with the RNA Clean Up RNeasy Minikit (Qiagen). Samples were concentrated by isopropanol precipitation and pellets were resuspended in $5 \mu \mathrm{l}$ RNAse-free water (Ambion, Austin, TX, USA).

\section{Microarray hybridization and data acquisition}

The concentrated labeled samples were mixed with $80 \mu \mathrm{l}$ hybridization buffer (HybBuffer \#1 from Ambion) and deposited on the microarray under a LifterSlip coverslip (Thermo Scientific, Mississauga, ON, Canada). Microarray incubation was conducted for $21 \mathrm{~h}$ at $50{ }^{\circ} \mathrm{C}$ in an automated station (the Slidebooster apparatus from Advalytix, Danvers, MA, USA).

The coverslips were then gently removed in a low-stringency buffer $(2 \times$ SSC $+0.5 \times$ SDS $)$. Slides were washed twice in the low-stringency buffer for $15 \mathrm{~min}$ at $50{ }^{\circ} \mathrm{C}$, transferred to highstringency buffer $(0.5 \times \mathrm{SSC}+0.5 \times \mathrm{SDS})$, and washed twice for $15 \mathrm{~min}$ at $50{ }^{\circ} \mathrm{C}$ and finally dipped quickly in a $1.25 \times \mathrm{SSC}$ solution and dried by centrifugation at $1200 \mathrm{~g}$ for $5 \mathrm{~min}$ at room temperature. Slides were read on a VersArray ChipReader (Bio-Rad). Image analysis was performed using ArrayPro software version 4.5 (MediaCybernetics, Bethesda, MD, USA). For each spot, background was determined locally. Data tables containing the foreground, background, and flagged spot annotation were generated for downstream data processing and statistical analyses.

\section{Quantitative RT-PCR measurements}

Additional pools of ten blastocysts per sample were collected for several treatments. Total RNA was extracted as described above. RT was conducted according to the manufacturer's recommendations using the qScript cDNA SuperMix (Quanta 
Biosciences, Gaithersburg, MD, USA) with an oligo-dT to prime the reaction.

Primers for each candidate were designed using the Primer3 Web interface (http://frodo.wi.mit.edu/primer3/). Primer sequence, annealing and fluorescence acquisition temperatures, amplicon size and GenBank accession numbers are shown in Table 2. The reaction mixture was composed of the LightCycler FastStart DNA Master SYBR Green I kit components (Roche) and real-time measurements were conducted in a LightCycler 2.0 apparatus (Roche). Our real-time PCR amplification procedure has previously been described in detail (Gilbert et al. 2010). The nature of the amplified products was confirmed using the melting curve profile and DNA sequencing.

\section{Data analysis}

Microarray data were pre-processed as follows: 1) background correction was conducted by simple subtraction; 2) mean values were calculated for the technically duplicated arrays; 3) median values were calculated for technically duplicated features spotted on the microarrays; 4) within-array normalization was performed with loess; 5) quantile was applied for inter-array normalization; and 6) the entire dataset was trimmed according to a cut-off value calculated from the mean values of selected negative control features (aliens, GFP, and arabidopsis) plus two S.D. Steps $3-5$ as well as the statistical analysis and all downstream steps were conducted in WebArrayDB (Xia et al. 2005, Wang et al. 2009): http://www. webarraydb.org/webarray/index.html.

The normalized and trimmed dataset was subjected to significance testing using the LIMMA algorithm (Smyth 2004, Smyth et al. 2005) using one of the treatments (or a group of treatments) as the reference. For contrasts set across all treatments, in vivo produced embryos were set as the reference. Adjusted $P$ values were calculated using the standard Benjamini-Hochberg method (Hochberg \& Benjamini 1990). Hierarchical clustering, heat maps, and between-group analyses (Culhane et al. 2002, 2003) were performed in WebArrayDB.

Pathway analyses and downstream exploitation of gene lists were conducted using Ingenuity Pathway Analysis Software Version 8.6 (Ingenuity Systems, Inc., Redwood City, CA, USA). For biological functions and canonical pathways, significance and threshold values were calculated using Fisher's exact test $(P<0.05)$. Only functions that included at least four candidates were selected Fig. 6, while a minimum of two genes was required for canonical pathways (Fig. 8).

For qRT-PCR data, normalization was performed using the geometric mean of several housekeeping candidates as proposed by Goossens et al. (2005). Calculations were performed using the geNorm Web platform (Vandesompele et al. 2002; http://medgen.ugent.be/ jvdesomp/genorm/). The housekeeping candidates included conserved helix-loop-helix ubiquitous kinase, glyceraldehyde-3-phosphate dehydrogenase, $\beta$-actin, tyrosine 3-monooxygenase/tryptophan 5-monooxygenase activation protein, zeta polypeptide in addition to a spiked in control mRNA bearing a poly $(\mathrm{A})$ tail (GFP transcript). Testing of statistical significance of observed differences was done using Prism software Version 5.0
(GraphPad Software, La Jolla, CA, USA). One-way ANOVA performed done using Kruskal-Wallis and Dunn's multiple comparison tests.

\section{Declaration of interest}

The authors declare that there is no conflict of interest that could be perceived as prejudicing the impartiality of the research reported.

\section{Funding}

This project was supported by funds from the Natural Sciences and Engineering Research Council of Canada.

\section{Acknowledgements}

The authors acknowledge the work of Dr Julie Nieminen (Université Laval, Canada) for linguistic revision.

\section{References}

Alm H, Torner H, Lohrke B, Viergutz T, Ghoneim IM \& Kanitz W 2005 Bovine blastocyst development rate in vitro is influenced by selection of oocytes by brillant cresyl blue staining before IVM as indicator for glucose-6-phosphate dehydrogenase activity. Theriogenology $\mathbf{6 3}$ 2194-2205. (doi:10.1016/j.theriogenology.2004.09.050)

Block J, Bonilla L \& Hansen PJ 2009 Effect of addition of hyaluronan to embryo culture medium on survival of bovine embryos in vitro following vitrification and establishment of pregnancy after transfer to recipients. Theriogenology 71 1063-1071. (doi:10.1016/j.theriogenology.2008.11. 007)

Bousquet D, Burnside EB \& Van Doormaal BJ 1998 Biotechnologies of reproduction applied to dairy cattle production: embryo transfer and IVF. Canadian Journal of Animal Science 83 403-407. (doi:10.4141/A03025)

Bousquet D, Twagiramungu H, Morin N, Brisson C, Carboneau G \& Durocher J 1999 In vitro embryo production in the cow: an effective alternative to the conventional embryo production approach. Theriogenology 51 59-70. (doi:10.1016/S0093-691X(98)00231-3)

Bui LC, Evsikov AV, Khan DR, Archilla C, Peynot N, Henaut A, Le Bourhis D, Vignon X, Renard JP \& Duranthon V 2009 Retrotransposon expression as a defining event of genome reprogramming in fertilized and cloned bovine embryos. Reproduction 138 289-299. (doi:10.1530/ REP-09-0042)

Crosier AE, Farin PW, Dykstra MJ, Alexander JE \& Farin CE 2000 Ultrastructural morphometry of bovine compact morulae produced in vivo or in vitro. Biology of Reproduction 62 1459-1465. (doi:10.1095/ biolreprod62.5.1459)

Culhane AC, Perriere G, Considine EC, Cotter TG \& Higgins DG 2002 Between-group analysis of microarray data. Bioinformatics 18 1600-1608. (doi:10.1093/bioinformatics/18.12.1600)

Culhane AC, Perriere G \& Higgins DG 2003 Cross-platform comparison and visualisation of gene expression data using co-inertia analysis. BMC Bioinformatics 4 59. (doi:10.1186/1471-2105-4-59)

Durocher J, Morin N \& Blondin P 2006 Effect of hormonal stimulation on bovine follicular response and oocyte developmental competence in a commercial operation. Theriogenology 65 102-115. (doi:10.1016/j. theriogenology.2005.10.009)

Fischer-Brown A, Monson R, Parrish J \& Rutledge J 2002 Cell allocation in bovine embryos cultured in two media under two oxygen concentrations. Zygote 10 341-348. (doi:10.1017/S0967199402004082)

Fujita T, Umeki H, Shimura H, Kugumiya K \& Shiga K 2006 Effect of group culture and embryo-culture conditioned medium on development of bovine embryos. Journal of Reproduction and Development 52 137-142. (doi:10.1262/jrd.16084) 
Gilbert I, Scantland S, Dufort I, Gordynska O, Labbe A, Sirard MA \& Robert C 2009 Real-time monitoring of aRNA production during T7 amplification to prevent the loss of sample representation during microarray hybridization sample preparation. Nucleic Acids Research 37 e65. (doi:10.1093/nar/gkp193)

Gilbert I, Scantland S, Sylvestre EL, Dufort I, Sirard MA \& Robert C 2010 Providing a stable methodological basis for comparing transcript abundance of developing embryos using microarrays. Molecular Human Reproduction 16 601-616. (doi:10.1093/molehr/gaq038)

Goossens K, Van Poucke M, Van Soom A, Vandesompele J, Van Zeveren A \& Peelman LJ 2005 Selection of reference genes for quantitative real-time PCR in bovine preimplantation embryos. BMC Developmental Biology 5 27. (doi:10.1186/1471-213X-5-27)

Gutierrez-Adan A, Rizos D, Fair T, Moreira PN, Pintado B, de la Fuente J, Boland MP \& Lonergan P 2004 Effect of speed of development on mRNA expression pattern in early bovine embryos cultured in vivo or in vitro. Molecular Reproduction and Development 68 441-448. (doi:10.1002/ $\operatorname{mrd}$.20113)

Guyader-Joly C, Ponchon S, Durand M, Heyman Y, Renard JP \& Menezo Y 1999 Effect of lecithin on in vitro and in vivo survival of in vitro produced bovine blastocysts after cryopreservation. Theriogenology 52 1193-1202. (doi:10.1016/S0093-691X(99)00211-3)

Hochberg Y \& Benjamini Y 1990 More powerful procedures for multiple significance testing. Statistics in Medicine 9 811-818. (doi:10.1002/sim. 4780090710)

Holm P, Booth PJ, Schmidt MH, Greve T \& Callesen H 1999 High bovine blastocyst development in a static in vitro production system using SOFaa medium supplemented with sodium citrate and myo-inositol with or without serum-proteins. Theriogenology 52 683-700. (doi:10.1016/ S0093-691X(99)00162-4)

Holm P, Booth PJ \& Callesen H 2002 Kinetics of early in vitro development of bovine in vivo- and in vitro-derived zygotes produced and/or cultured in chemically defined or serum-containing media. Reproduction 123 553-565. (doi:10.1530/rep.0.1230553)

Kimura K, Spate LD, Green MP \& Roberts RM 2005 Effects of D-glucose concentration, D-fructose, and inhibitors of enzymes of the pentose phosphate pathway on the development and sex ratio of bovine blastocysts. Molecular Reproduction and Development 72 201-207. (doi:10.1002/mrd.20342)

Kimura K, Iwata H \& Thompson JG 2008 The effect of glucosamine concentration on the development and sex ratio of bovine embryos. Animal Reproduction Science 103 228-238. (doi:10.1016/j.anireprosci. 2006.12.014)

Knijn HM, Wrenzycki C, Hendriksen PJ, Vos PL, Herrmann D, van der Weijden GC, Niemann H \& Dieleman SJ 2002 Effects of oocyte maturation regimen on the relative abundance of gene transcripts in bovine blastocysts derived in vitro or in vivo. Reproduction $\mathbf{1 2 4}$ 365-375. (doi:10.1530/rep.0.1240365)

Knijn HM, Wrenzycki C, Hendriksen PJ, Vos PL, Zeinstra EC, van der Weijden GC, Niemann H \& Dieleman SJ 2005 In vitro and in vivo culture effects on mRNA expression of genes involved in metabolism and apoptosis in bovine embryos. Reproduction, Fertility, and Development 17 775-784. (doi:10.1071/RD05038)

Le Bouc Y, Rossignol S, Azzi S, Steunou V, Netchine I \& Gicquel C 2010 Epigenetics, genomic imprinting and assisted reproductive technology. Annales d'Endocrinologie 71 237-238. (doi:10.1016/j.ando.2010.02. 004)

Leese HJ 2002 Quiet please, do not disturb: a hypothesis of embryo metabolism and viability. Bioessays 24 845-849. (doi:10.1002/bies. 10137)

Leese HJ, Sturmey RG, Baumann CG \& McEvoy TG 2007 Embryo viability and metabolism: obeying the quiet rules. Human Reproduction 22 3047-3050. (doi:10.1093/humrep/dem253)

Leese HJ, Baumann CG, Brison DR, McEvoy TG \& Sturmey RG 2008 Metabolism of the viable mammalian embryo: quietness revisited. Molecular Human Reproduction 14 667-672. (doi:10.1093/molehr/ gan065)

Lonergan P, Rizos D, Gutierrez-Adan A, Fair T \& Boland MP 2003 Effect of culture environment on embryo quality and gene expression experience from animal studies. Reproductive Biomedicine Online 7 657-663. (doi:10.1016/S1472-6483(10)62088-3)
Luciano AM, Pocar P, Milanesi E, Modina S, Rieger D, Lauria A \& Gandolfi F 1999 Effect of different levels of intracellular cAMP on the in vitro maturation of cattle oocytes and their subsequent development following in vitro fertilization. Molecular Reproduction and Development 54 86-91. (doi:10.1002/(SICl)1098-2795(199909)54:1< 86::AID-MRD13>3.0.CO;2-C)

McEvoy TG, Sinclair KD, Young LE, Wilmut I \& Robinson JJ 2000 Large offspring syndrome and other consequences of ruminant embryo culture in vitro: relevance to blastocyst culture in human ART. Human Fertility 3 238-246. (doi:10.1080/1464727002000199061)

McHughes CE, Springer GK, Spate LD, Li R, Woods R, Green MP, Korte SW, Murphy CN, Green JA \& Prather RS 2009 Identification and quantification of differentially represented transcripts in in vitro and in vivo derived preimplantation bovine embryos. Molecular Reproduction and Development 76 48-60. (doi:10.1002/mrd.20929)

Menck MC, Guyader-Joly C, Peynot N, Le Bourhis D, Lobo RB, Renard JP \& Heyman Y 1997 Beneficial effects of Vero cells for developing IVF bovine eggs in two different coculture systems. Reproduction, Nutrition, Development 37 141-150. (doi:10.1051/rnd:19970202)

Mohan M, Hurst AG \& Malayer JR 2004 Global gene expression analysis comparing bovine blastocysts flushed on day 7 or produced in vitro. Molecular Reproduction and Development 68 288-298. (doi:10.1002/ $\operatorname{mrd} .20086)$

de Moraes AA \& Hansen PJ 1997 Granulocyte-macrophage colonystimulating factor promotes development of in vitro produced bovine embryos. Biology of Reproduction 57 1060-1065. (doi:10.1095/ biolreprod57.5.1060)

Niemann H \& Wrenzycki C 2000 Alterations of expression of developmentally important genes in preimplantation bovine embryos by in vitro culture conditions: implications for subsequent development. Theriogenology 53 21-34. (doi:10.1016/S0093-691X(99)00237-X)

Pereira MM, Machado MA, Costa FQ, Serapiao RV, Viana JH \& Camargo LS 2010 Effect of oxygen tension and serum during IVM on developmental competence of bovine oocytes. Reproduction, Fertility, and Development 22 1074-1082. (doi:10.1071/RD10007)

Purpera MN, Giraldo AM, Ballard CB, Hylan D, Godke RA \& Bondioli KR 2009 Effects of culture medium and protein supplementation on mRNA expression of in vitro produced bovine embryos. Molecular Reproduction and Development 76 783-793. (doi:10.1002/mrd.21028)

Rizos D, Gutierrez-Adan A, Perez-Garnelo S, De La Fuente J, Boland MP \& Lonergan P 2003 Bovine embryo culture in the presence or absence of serum: implications for blastocyst development, cryotolerance, and messenger RNA expression. Biology of Reproduction 68 236-243. (doi:10.1095/biolreprod.102.007799)

Rizos D, Clemente M, Bermejo-Alvarez P, de La Fuente J, Lonergan P \& Gutierrez-Adan A 2008 Consequences of in vitro culture conditions on embryo development and quality. Reproduction in Domestic Animals 43 (Suppl 4) 44-50. (doi:10.1111/j.1439-0531.2008.01230.x)

Robert C 2010 Microarray analysis of gene expression during early development: a cautionary overview. Reproduction 140 787-801. (doi:10.1530/REP-10-0191)

Robert C, Barnes FL, Hue I \& Sirard MA 2000 Subtractive hybridization used to identify mRNA associated with the maturation of bovine oocytes. Molecular Reproduction and Development 57 167-175. (doi:10.1002/ 1098-2795(200010)57:2 <167::AID-MRD8 > 3.0.CO;2-P)

Rougeulle C \& Avner P 2004 The role of antisense transcription in the regulation of X-inactivation. Current Topics in Developmental Biology 63 61-89. (doi:10.1016/S0070-2153(04)63003-1)

Santos F, Hyslop L, Stojkovic P, Leary C, Murdoch A, Reik W, Stojkovic M, Herbert M \& Dean W 2010 Evaluation of epigenetic marks in human embryos derived from IVF and ICSI. Human Reproduction 25 2387-2395. (doi:10.1093/humrep/deq151)

Seli E, Robert C \& Sirard MA 2010 OMICS in assisted reproduction: possibilities and pitfalls. Molecular Human Reproduction 16 513-530. (doi:10.1093/molehr/gaq041)

Senner CE \& Brockdorff N 2009 Xist gene regulation at the onset of X inactivation. Current Opinion in Genetics \& Development 19 122-126. (doi:10.1016/j.gde.2009.03.003)

Smyth GK 2004 Linear models and empirical bayes methods for assessing differential expression in microarray experiments. Statistical Applications in Genetics and Molecular Biology 3 Article3. (doi:10.2202/1544-6115. 1027) 
Smyth GK, Michaud J \& Scott HS 2005 Use of within-array replicate spots for assessing differential expression in microarray experiments. Bioinformatics 21 2067-2075. (doi:10.1093/bioinformatics/bti270)

Stojkovic M, Kolle S, Peinl S, Stojkovic P, Zakhartchenko V, Thompson JG, Wenigerkind H, Reichenbach HD, Sinowatz F \& Wolf E 2002 Effects of high concentrations of hyaluronan in culture medium on development and survival rates of fresh and frozen-thawed bovine embryos produced in vitro. Reproduction 124 141-153. (doi:10.1530/ rep.0.1240141)

Taverne MA, Breukelman SP, Perenyi Z, Dieleman SJ, Vosa PL, Jonker HH, de Ruigh L, Van Wagtendonk-de Leeuw JM \& Beckers JF 2002 The monitoring of bovine pregnancies derived from transfer of in vitro produced embryos. Reproduction, Nutrition, Development 42 613-624. (doi:10.1051/rnd:2002047)

Vallee M, Dufort I, Desrosiers S, Labbe A, Gravel C, Gilbert I, Robert C \& Sirard MA 2009 Revealing the bovine embryo transcript profiles during early in vivo embryonic development. Reproduction 138 95-105. (doi:10.1530/REP-08-0533)

Vandesompele J, De Preter K, Pattyn F, Poppe B, Van Roy N, De Paepe A \& Speleman F 2002 Accurate normalization of real-time quantitative RT-PCR data by geometric averaging of multiple internal control genes. Genome Biology 3 RESEARCH0034. (doi:10.1186/gb-2002-3-7research0034)

Vigneault C, Gravel C, Vallee M, McGraw S \& Sirard MA 2009 Unveiling the bovine embryo transcriptome during the maternal-to-embryonic transition. Reproduction 137 245-257. (doi:10.1530/REP-08-0079)

van Wagtendonk-de Leeuw AM, Mullaart E, de Roos AP, Merton JS, den Daas JH, Kemp B \& de Ruigh L 2000 Effects of different reproduction techniques: AI MOET or IVP, on health and welfare of bovine offspring. Theriogenology 53 575-597. (doi:10.1016/S0093-691X(99) 00259-9)

Wang Y, McClelland M \& Xia XQ 2009 Analyzing microarray data using WebArray. Cold Spring Harbor Protocols 2009 pdb.prot5260. (doi:10. 1101/pdb.prot5260)

Wrenzycki C, Herrmann D, Carnwath JW \& Niemann H 1998 Expression of RNA from developmentally important genes in preimplantation bovine embryos produced in TCM supplemented with BSA. Journal of Reproduction and Fertility 112 387-398. (doi:10.1530/jrf.0.1120387)

Wrenzycki C, Herrmann D, Keskintepe L, Martins A Jr, Sirisathien S, Brackett B \& Niemann H 2001 Effects of culture system and protein supplementation on mRNA expression in pre-implantation bovine embryos. Human Reproduction 16 893-901. (doi:10.1093/humrep/16. 5.893)

Xia X, McClelland M \& Wang Y 2005 WebArray: an online platform for microarray data analysis. BMC Bioinformatics 6 306. (doi:10.1186/ 1471-2105-6-306)

Young LE, Sinclair KD \& Wilmut I 1998 Large offspring syndrome in cattle and sheep. Reviews of Reproduction 3 155-163. (doi:10.1530/ror.0. 0030155)

Received 22 November 2010

First decision 3 February 2011

Revised manuscript received 10 March 2011

Accepted 12 April 2011 